\title{
Modernization of the Energy System of an Enterprise
}

\author{
Alexey Vladimirovich Sklyar ${ }^{1}$, Tatyana Evgenievna Marinchenko ${ }^{2}$ \\ ${ }^{1}$ Big Dutchman LLC, Moscow, the Russian Federation \\ ${ }^{2}$ Russian Research Institute of Information and Feasibility Study on Engineering Support of Agribusiness, The Federal State Budgetary \\ Scientific Institution (Rosinformagrotekh FSBSI), Pravdinsky Township, Moscow Region, the Russian Federation
}

Email address:

Vskliar41@mail.ru(A.V. Sklyar),9419428@mail.ru (T. E. Marinchenko)

\section{To cite this article:}

Alexey Vladimirovich Sklyar, Tatyana Evgenievna Marinchenko. Modernization of the Energy System of an Enterprise. American Journal of Agriculture and Forestry. Vol. 7, No. 4, 2019, pp. 133-138. doi: 10.11648/j.ajaf.20190704.12

Received: April 8, 2019; Accepted: May 20, 2019; Published: July 16, 2019

\begin{abstract}
Energy saving in any enterprise is an actual problem associated with the rising cost of energy. In this case, the cost of electricity is among the most expensive components. One of the most effective ways to save electricity is to use energysaving technologies and modernize energy systems, including using "small" energy systems. The task was to modernize the energy system of the Cherepovets poultry farm in order to reduce energy costs. After completing the cycle of work on a comprehensive assessment of possible options, production verification and implementation, the most effective way to reduce the cost of electricity was the method of upgrading the energy system based on "small generation" means using traditional fuels. The modernization allowed the Cherepovets poultry farm to annually generate up to one-third of its own electricity through a mini-combined heat and power station (mini-CHP) and keep the cost of the kWh generated three times lower than that in the grid. It confirmed the possibility of sharing the poultry farm and grids of its 6 (10) $\mathrm{kV}$ transmission lines and transformer substation on the territory of the farm.
\end{abstract}

Keywords: Energy Conservation, Modernization, Energy Systems, Heat Exchangers, Mini-combined Heat and Power Stations (Mini-CHP)

\section{Introduction}

The level of energy efficiency of agricultural production largely determines the cost of production. The share of energy consumption in the cost estimates of agricultural enterprises for the production of agricultural products is a significant part (from 10 to $50 \%$ ), and taking into account the growth rates of energy carriers cost, the implementation of energy saving measures in increasing the energy efficiency of agricultural production takes on particular importance, especially in conditions of competition with foreign enterprises, where a higher level of technology and labor productivity exists [1].

Spending on energy, the main share of which is the payment of electricity, is in the third place in the cost of poultry products after the cost of feed and wages [2]. Until recently, the annual consumption of electricity, for example, by a poultry farm outputting 14,000-15,000 metric tons of meat per year, was 16-19 million $\mathrm{kWh}$. Broiler houses had up to $70 \%$ of the load accounted for the microclimate (brooders, ventilation, etc.), $25 \%$ for lighting (incandescent lamps), the rest for feed distribution and other process steps. With the introduction of LED lighting, ventilation systems based on the principles of vacuum with less energy-intensive axial fans (such as VO-12), this ratio has changed, but the continuous increase in energy prices leaves the issue of reducing the cost of energy components among the most relevant [3, 4].

During the period of reforming the Unified Energy System of the Russian Federation, it was assumed that the division of generation, suppliers and distributors, while creating market conditions for the consumer, would allow the latter to freely choose suppliers according to the "price-quality" criterion and reduce costs for this cost item. However, a number of difficulties, in particular related to the specifics of livestock production, deprive the producer of a choice.

Nevertheless, producers carry out energy-saving measures that can significantly reduce energy costs, and this immediately affects the increase in profitability and competitiveness by reducing the cost of products or services.

A cycle of work on comprehensive assessment of possible 
options, production verification and implementation of the most efficient method of reducing electricity costs based on the use of heat-saving technologies and "small" energy systems was performed with the involvement of independent specialists in the poultry enterprises of the Vologda Oblast.

\section{Method}

The Cherepovets poultry farm was tasked with reducing the cost of electricity. With the involvement of independent specialists, the workers of the APK-OGO JSC agroholding completed a cycle of work on a comprehensive assessment of possible options, modeling, production verification and the introduction of the most effective method of reducing electricity costs.

\subsection{Immediacy of the Problem}

Energy conservation in the poultry industry is devoted to many works of researchers. There are more widely covered solutionsfor energy saving in the field of lighting that give a good economic effect during implementation (Bayneva, I. I., Khisaev, I. A., Nagimov, A. Kh., Sakayev, R. A., Yanbekov, N. R., Konyaev, N. V., Lytkina, E. N., Firsov, V. S., Grishin, K. M., Chvanov, Ya. S., Malyshev, V. V. et al.), heat savings, in particular, for reducing heat loss from structural members of buildings and ventilation air (Piir, A. E., Kozak, O. A., Kuntysh, V. B. et al.), for autonomous heating and power supply, including using "small" generations (Sukhov, A. A., Stushkina, N. A. et al.). Papers on the modernization of the energy system of an enterprise based on heat-saving technologies with the use of "small" energy sources were not found.

\subsection{Theoretical Part}

To solve this problem, the following possibilities were considered to reduce costs while providing the poultry farm with the necessary annual amount of electric power: switching to multi-zone tariffs with installing the Automated Power Consumption Information and Fiscal Metering System (APCIFMS); transfer of the farm's power supply to a higher voltage; output of the poultry farm to the wholesale electricity and capacity market; change of the last resort supplier (LRS); "small generation" using traditional fuels among others, i.e. production at the farm of the required annual amount of electricity at prices lower than the grid ones.

For the first group, only zoning was analyzed (within the $1^{\text {st }}$ and $2^{\text {nd }}$ price categories), since the possible effect of tworate prices with payment for power is incomparably small. Calculations for all options two-zone (night-day) and threezone prices (night-half-peak-peak) showed that the transition from single-zone payment to two-zone and three-zone calculations does not save on the consumed electricity for poultry farms, which is connected with the specifics of production: the main energy-intensive processes (ventilation, lighting, heating of poultry houses with livestock, as well as incubation of eggs, operation of refrigerators and freezers, waste water treatment facilities go round-the-clock and all- season, excluding all possibilities of shifting these operations by the time of day. The few processes (for example, filling the reservoir of a pressure tower, etc.) that can be transferred to night hours against the background of the overall energy consumption of the poultry farm are not significant in terms of amount, and the cost of more complex accounting disproportionately high [5].

Modeling the transfer of the poultry farm to receive electricity from higher voltage grids at preferential prices has showed that tariffs do provide for differentiated payment for receiving by the customer the electricity in four categories: high voltage (110 $\mathrm{kV}$ and above), medium voltage (MV1) (35 kV) and MV2 (20 to $1 \mathrm{kV}$ ), and low voltage (below 1 $\mathrm{kV})$. When modeling, the Sheksninskaya poultry farm was included into the group of estimated poultry farms, which for a number of objective reasons had been fed non-traditionally during construction, namely, through a $110.10 \mathrm{kV}$ load center substation and retained the assembly service on the high voltage side (voltage coming to the primary winding of the transformer from the side, for example, of power lines). As a rule, this voltage is higher than that removed from the secondary winding of a transformer in this transformer substation. The poultry farm has qualified personnel with access to work at high voltage and pays for electricity at the lowest rate. Prices on the scale of annual consumption of more than $10 \mathrm{MVA}$ for the purchase of $1 \mathrm{kWh}$ are by $20 \%$ forMV2, by $27 \%$ for MV1, and by $37 \%$ for high voltage less than for low voltage. The effective use of this benefit is convincingly confirmed by the long-term practice of using such a scheme to save electricity costs at the Sheksninskaya poultry farm. However, it should be noted that the widespread introduction of this method of saving at poultry farms is unlikely: since 1991, many enterprises, going bankrupt, have lost not only high-voltage transformer stations and MV1, but also MV2; and only $0.4 \mathrm{kV}$ power lines are operated. It is unlikely to return high-voltage transformer substations to poultry farms now.

To enter the Register of Participants of the Federal Wholesale Power and Capacity Market (FWPCM) having received savings on the sales margin, the consumer's power system must meet a number of requirements, the main of which are: it is necessary to have 20 MVA or more of connected power with at least 0.75 MVA capacity of the most low-power transformer substation; the equipment of the consumer's power supply system must be equipped with APCIFMS, etc. [6].

The largest poultry farms of the Russian Federation meet the requirements for total capacity; these areSinyavino, Volzhanin, Roskar, Irtyshskaya and even more than a dozen egg enterprises with millions of flocks of laying hens, as well as all broiler enterprises producing 100,000-150,000 metric tons and more of meat per year (Mikhailovskoye, BZRK, PFSevernaya, etc.). However, the specifics of the poultry enterprise, in accordance with the RD-APK 3.10.07.02-14, have divided the territory of each poultry farm with a number of sanitary zones (300 m wide each) to ensure zoo-veterinary breaks. This led to the powering of workshops in these areas 
through a network of transformer substations of $10(6) / 0.4 \mathrm{kV}$. As a result, even medium-sized poultry farms with a connected capacity of 13-19 MVA have dozens of transformer substations (ShPF-19, ChPF-24) and a significant portion of them with a capacity of up to $0.75 \mathrm{MVA}$. The same situation is in large poultry farms and associations, and therefore their access to FWPCM is a problem [7, 8].

Modeling for a number of opportunities to save money on electricity supply by changing the last resort supplier showed the following. Procedurally supplier change is possible in the conditions of any farm. The very savings from a supplier change may consist in reducing the value of the marketing margin (but it is small and is $2-2.5 \%$ on average of the price of $1 \mathrm{kWh}$ ) and in the best case, with cheaper delivery, the same addition will be for transportation. Such coincidences are possible (equidistance, the presence of a parallel $35 \mathrm{kV}$ power transmission line, etc.), but in general it is a factor of rather limited capabilities [9].

There is also an area of "small" energy. The Russian Federation has more than $232 \mathrm{GW}$ of generating capacity, of which $2 / 3$ is heat plants and most of them run on gas. Since the development of new fields, the extraction and laying of the northern gas pipelines require a large amount of investment, it appears that the cost of gas will increase all the time in the near future, and the cost of the "gas" $\mathrm{kWh}$, as a secondary product, will have a faster growth. Therefore it is not by chance that Article 29, Clause 2 of the federal law No. 35-FZ of March 26, 2003 "On Electric Power Industry", emphasizes that the basis of the state policy for further development of the electric power industry is the use of new areas (non-traditional renewable energy resources, such as sun, wind, tides, etc.), as well as the use of "small" energy. "Small" energy means local (autonomous by enterprise, locality) power systems, including those running on traditional fuels [10-13].

The economic legitimacy of small systems is based on the fact that the calorific value of $1 \mathrm{~nm} 3$ of gas according to GOST5544-2014 is $8,000 \mathrm{kcal}$, which, without taking into account the transformation efficiency, is equivalent to $8,000 / 860=9.3 \mathrm{kWh}$ of electricity. Taking into account the working range of efficiency variation, the electricity generation at mini-power plants will be in the range of 2.5$3.8 \mathrm{kWh}$ per $1 \mathrm{~nm} 3$ of gas $[14,15]$.

Modeling the use of "small" energy means acceptable for most farms, it is necessary to proceed from the following provisions:

1. Most farms own only low voltage electricity

2. Level of permissible replacement of grid electricity with own generation should be such that funds from the supply of the rest of electricity would be enough to renovate the entire grid structure at the poultry plant $(6$ (10) / $0.4 \mathrm{kV}$ substation and 6 (10) $\mathrm{kV}$ power transmission line), ensuring the salaries of employees and a certain level of profit [16].

Modeling and calculations showed that for a quick recoupment of a mini-combined heat and power station (mini-CHP), it is necessary to install it in separate workshops (areas) with an extremely high daily demand factor for connected loads, as well as to select the generator power for the loads of a specific section (parent flock, young stock or a part of the product area). For example, 18 floor-standing broiler houses require $315 \mathrm{~kW}$, etc. Under these conditions, mini-CHP is capable of producing up to 2.4-2.7 million $\mathrm{kWh}$ per year, providing electricity for the production of 10,000 metric tons of broiler meat; two such power plants are capable of producing up to 20,000 metric tons, etc.

Figure 1 shows the connection diagram of a container mini-CHP at the existing $6(10) \mathrm{kV}$ transformer substation to the low voltage power line belonging to the poultry farm, with disconnecting the isolator on the low voltage bus bars of the transformer substation.

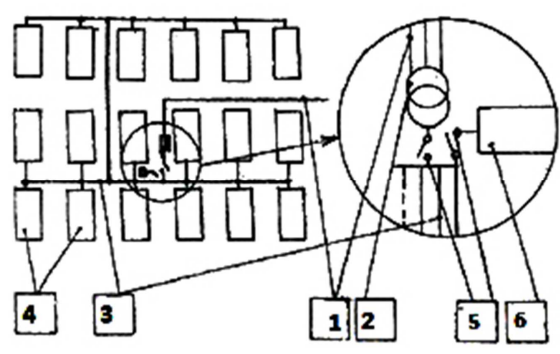

Figure 1. Wiring diagram for connection to the low voltage networks. Legend: 1 -6 (10) kV power transmission line; 2 - 6 (10) $10.4 \mathrm{kV}$ transformer; $3-0.4 \mathrm{kV}$ power transmission line; 4 - electricity consumer (poultry houses); 5- low voltage isolators: power grid and consumer (gas piston engine + electric generator); 6 - mini-CHP (gas piston engine + electric generator).

It should be noted that electrical reconnection in this case occurs in the legal ownership of the poultry farm, i.e. on low voltage lines; no permitting regulatory documents are required. Electric networks with transformer substations and $6(10) \mathrm{kV}$ transmission lines remain at farms for the constant supply of the rest of the electricity and serve as a backup for the entire farm. To commission a mini-CHP, it is necessary to connect it to the pipeline gas with the design and installation work to be carried out by the specialists of the regional gas networks. According to $315 \mathrm{~kW}$ connected power of a mini$\mathrm{CHP}$, the gas demand will be $110 \mathrm{~m} 3 / \mathrm{h}$, which is approximately equal to the hourly need for 2 to 2.2 broiler houses and can be obtained by reducing gas consumption at just a few poultry houses served by mini-CHP provided that heat recovery facilities are installed at them $[17,18]$.

The heat exchangers introduced at the farm showed high efficiency: the $0{ }^{\circ} \mathrm{C}$ air flow was applied to the reheat heater at an outside air temperature of minus $15{ }^{\circ} \mathrm{C}$. This allowed the farm for several years to reconstruct the ventilationheating system for heat recovery units and utilize heat in $81 \%$ of poultry houses at the poultry farm (45 buildings). The large-scale re-equipment enabled the farm to reduce the annual heat consumption by a third $(79,000 \mathrm{Gcal}$ instead of 119,700 Gcal) in comparison with broiler factories of comparable capacity $(13,500-15,000$ metric tons a year) of a similar climatic zone.

The overall heat savings allowed the poultry farm to put into operation the necessary number of mini-CHPs without 
obtaining permits from gas farms to increase annual gas consumption $[19,20]$.

This technique was tested during the inspection of a miniCHP option at the Cherepovets poultry farm (the main collaborators were V. Minaev and V. Mokhov). The farm began to save substantial amounts of heat (and gas) through installing heat recovery units on a large number of poultry houses. One of the DKVR steam boilers (double-drum vertically-water-tube reconstructed unit) at the boiler house of the poultry farm was freed from the load. This made it possible to install a steam turbine generator (STG) having a capacity of 1.25 MW (Proletarsky Zavod PJSC, St. Petersburg) in a separate room at the boiler room and eliminate all problems of limits on the amounts and connections of the mini-CHPs on the gas side (STG parameters fit well with the DKVR boiler at an output pressure up to $2.5 \mathrm{MPa}$ and steam temperature up to $370^{\circ} \mathrm{C}$, as well as at a pressure behind the turbine of $0.6-0.12$ $\mathrm{MPa}$ [ $[21,22]$.

With the implemented scheme, it was necessary to solve the problem of the possibility of joint operation with the power grid, since it is impossible to transfer $1,250 \mathrm{~kW}$ of electricity to several sections that were remote from the boiler room more than $300 \mathrm{~m}$ via low voltage lines, and because the electric generators having a capacity of $1.25 \mathrm{MW}$ were high voltage ones.

\section{Result}

The long-term operation of the mini-CHP at the Cherepovets poultry farm with annual generation of up to one-third of its own electricity (up to 4 million $\mathrm{kWh}$ with an annual amount of electricity consumption of 12 to $13 \mathrm{mln}$ $\mathrm{kWh}$ ) has allowed the cost of kilowatt-hours to be kept at three times lower than that of the grid. It has confirmed the possibility of sharing by the power lines of the poultry farm its6 (10) $\mathrm{kV}$ power transmission line and transformer substations at the premises (it is necessary to measure the "overflows" and plan the flow directions).

The mini-CHP scheme with a gas piston engine and an electric generator (according to Figure 2) and later implemented by the Sredneuralskaya poultry farm showed itself as the most efficient.

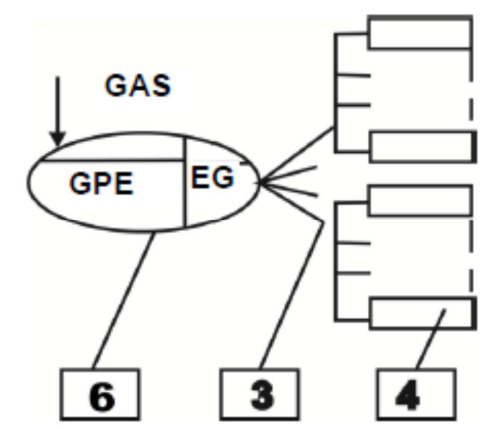

Figure 2. Mini-CHP diagram Legend: $3-0.4 \mathrm{kV}$ power transmission line; 4 - electricity loads (poultry buildings); mini-CHP (gas piston engine + electrical generator).

\section{Discussion}

It should be noted that foreign gas piston engines have quite high engine service hours (Wilson) equal to 170,000 to 180,000 hours of operating time (this is more than 21.1 yearswith 2 overhauls), at the same time, domestic gas piston engines are close to foreign ones in these indicators (Rybinsk Complex, Russian Diesel, Balakovo). Those enterprises that do not have pipeline gas can use mini-CHP running on crude oil (Konver LLC and KolomenskyZavodOJSC) [23, 24]. Table 1 shows the specifications of such power plants

Table 1. Specifications of container-mounted mini-CHP running on gas and crude oil.

\begin{tabular}{|c|c|c|c|c|c|}
\hline \multirow{2}{*}{ Parameters } & \multicolumn{5}{|c|}{ Power plant model } \\
\hline & EGP $100 K$ & $E G N 200 K^{*}$ & EGP 200K & $E G N 315 K^{*}$ & EGP $315 K$ \\
\hline Rated electric power $(\mathrm{kW})$ & 100 & 200 & 200 & 315 & 315 \\
\hline Rated voltage $(\mathrm{kV})$ & $0.4 / 0.22$ & $0.4 / 0.22$ & $0.4 / 0.22$ & $0.4 / 0.22$ & $0.4 / 0.22$ \\
\hline Frequency $(\mathrm{Hz})$ & 50 & 50 & 50 & 50 & 50 \\
\hline Heat recovery unit power $(\mathrm{kW})$ & 150 & 250 & 250 & 460 & 460 \\
\hline including that for exhaust gas recovery (kW) & 55 & 105 & 105 & 170 & 170 \\
\hline Fuel consumption & $35 \mathrm{Nm}^{3} / \mathrm{h}$ & $5.5 \mathrm{~L} / \mathrm{h}$ & $70 \mathrm{Nm}^{3} / \mathrm{h}$ & $8.0 \mathrm{~L} / \mathrm{h}$ & $110 \mathrm{Nm}^{3} / \mathrm{h}$ \\
\hline
\end{tabular}

*Note: EGN runs on crude oil (backup is furnace oil and diesel fuel), the rest ones use pipeline gas as the base fuel.

Table 2 shows the cost efficiency of the EGP operation.

Table 2. Cost efficiency of the EGP operation.

\begin{tabular}{lll}
\hline \multirow{2}{*}{ Parameters } & Power plant model & \\
\cline { 2 - 3 } & EGP 100K & EGP 200K \\
\hline Cost of EGP in basic configuration, '000 rubles & $2,554.18$ & $3,776.82$ \\
General CAPEX with local grids & $3,509.26$ & $4,731.90$ \\
General expenditures for EGP operation, '000 rubles & $1,370.68$ & $5,309.19$ \\
Annual own electricity generation, $k W h$ & 670,140 & $2,056.51$ \\
Cost of annual own electricity generation amount, '000 rubles & $2,345.49$ & $1,340,280$ \\
Prime cost of own electricity, rubles/ $\mathrm{kWh}$ & 2.046 & $4,690.98$ \\
Payback time, years & 3.65 & 1.534 \\
\hline
\end{tabular}




\section{Conclusion}

At the Cherepovets poultry farm, a comprehensive assessment of possible options, production verification and the introduction of the most effective method of reducing electricity costs, namely, the so-called "small generation" using traditional types of fuel, i.e. production at the factory of the required annual amount of electricity at prices lower than the grid prices were performed.

The simulation showed that in order to provide the shortest payback time, the mini-CHPs should be installed into separate sections with an extremely high daily demand factor for connected loads and the generator power should be selected for the loads of a specific area. Under these conditions, a mini-CHP is capable of producing up to 2.4 to $2.7 \mathrm{mln} \mathrm{kWh}$ per year.

To commission a mini-CHP, it is necessary to connect it to the pipeline gas with the performance of design and installation work. According to the $315 \mathrm{~kW}$ mini-CHP connected power, the gas demand will be $110 \mathrm{~m} 3 / \mathrm{h}$, which can be obtained by reducing the gas consumption when installing heat recovery units. This method allows the poultry factory to put into operation the necessary number of miniCHPs without obtaining permits to increase the annual gas consumption.

The Cherepovets poultry plant began to save substantial amounts of heat (and gas) by installing heat recovery units at a large number of poultry houses, so that one of the DKVR steam boilers was without any load. This made it possible to install a $1.25 \mathrm{MW}$ steam turbine generator in a separate room at the boiler house and eliminate the problems of limits to the mini-CHP gas amount and connection.

A poultry farm that has no pipeline gas mini-CHP scan be used that run on crude oil (Konver LLC and Kolomensky Zavod OJSC) can be used. The modernization allowed the Cherepovets poultry farm to produce annually, by means of a mini-CHPs, up to one third of its own electricity, to keep the cost price of the generated $\mathrm{kWh}$ three times lower than the grid cost price. It confirmed the possibility of sharing the poultry farm and grids of its $6(10) \mathrm{kV}$ transmission lines and transformer substation on the territory of the farm.

\section{References}

[1] Strebkov, D. S. Improving the energy efficiency of the use of fuel and energy resources in agriculture of Russia / D. S. Strebkov, A. V. Tikhomirov // Scientific and technical progress in agricultural production: Proceedings of international scientific-practical conference (Minsk, October 19-20, 2010). - Minsk: Scientific and Practical Center of the National Academy of Sciences of Belarus on Agricultural Mechanization, the Republican Unitary Enterprise, 2010. - p. 18-24.

[2] Buyarov, V.S. Broiler poultry farming: from technology to economy / V.S. Buyarov, V. V. Balashov, A. V. Buyarov // Agrarian Scientific Journal. - 2014. No. 6. - p. 6-9.
[3] Marinchenko, T. E. State and trends of the poultry industry in Russia // Innovative support of egg and meat poultry farming in Russia: Proceedings of XVIII International conference (Sergiev Posad, May 19-21, 2015). - Sergiev Posad. - 2015. p. 551-553.

[4] Fisinin, V. I. Industrial poultry farming / V. I. Fisinin [et al.]; scientific editor: Fisinin, V. I. - Moscow, 2016. -pp. 534.

[5] The choice of the price category of electricity - URL: https://en-mart.com/vybor-cenovoy-kategorii-elektroenergii/ (accessed on 01.09.2018).

[6] Tariff policy - URL: http://www.rosteplo.ru/Tech_stat/stat_shablon.php?id=338 (accessed on 11/20/2018).

[7] RD-APK 3.10.07.02-14 Methodological guide for veterinary examination of projects of livestock facilities - URL: http://docs.cntd.ru/document/1200127148 (accessed on $11 / 20 / 2018)$.

[8] Tuksin, A. A. Problems of minimizing the cost of electricity supply for small and medium-sized businesses and their solutions // Volga Trade and Economic Journal. - 2011. -No. 2. - p. 47-50.

[9] The procedure for changing the last resort supplier - URL: https://www.np-

sr.ru/sites/default/files/01_2018_procedura_smeny_gp_itog_n a_sayt.pdf (accessed on 02.12.2018).

[10] Federal LawNo. 35-FZ "On Electric Power Industry" dated March 26, 2003 (last revised) - URL: http://www.consultant.ru/document/cons doc LAW 41502/ (accessed on November 20, 2018).

[11] Dorokhin, V. N. New technologies in power engineering / V. N. Dorokhin, A. A. Soloviev, A. A. Timofechev, A. G. Rozhkov. - Omsk: Siberian State Automobile and Highway University, 2018. -pp. 33.

[12] Belova, E. A. Self-contained energy sources in power supply systems / E. A. Belova, A. P. Kuznetsov // Electric engineering. Energy. Engineering: Collection of scientific papers of I Int. scientific conf. of young scientists. Novosibirsk: Novosibirsk State Technical University. - 2014. p. 225-228.

[13] Kozlov, E. A. The main directions of development of small distributed energy / Ye. A. Kozlov, I. B. Sheshenya, A. G. Zelenin // Youth and Scientific and Technological Progress: IX Int. scientific-practical. conf. of students, graduate students and young scientists. - Stary Oskol: Assistant Plus LLC. 2016. - p. 130-132.

[14] GOST 29322-2014 (IEC 60038: 2009) Standard voltages URL: https://electromontaj-proekt.ru/data/documents/gost29322-2014.pdf (accessed on 05.12.2018).

[15] Marinchenko, T. E. Implementation of innovative projects in agriculture: experience and prospects / T. E. Marinchenko, V. N. Kuzmin, A. P. Korolkova. - M., 2017. -pp. 80.

[16] Vodyannikov, V. T. Feasibility study of small energy in the agribusiness: textbook for universities. - / V. T. V-dyannikov, A. V. Shakhi study guide: [for universities in the specialty "Electrification and automation of agriculture"] / V. T. Vodyannikov, A. V. Shakhov. - Moscow: Moscow State. agroengineering un them. V. P. Goryakina, 2010. - p. 162. 
[17] Technical description and planning guide of the miniCHPsrunning on natural gas - URL: http://www.tpsr.ru/upload/iblock/858/85851f624dd161e3584d 97105cc81073.pdf (accessed on 02.12.2018).

[18] Khisamov, A. K. How to manage energy costs in broiler poultry // Poultry and poultry products. - 2011. -No. 1. - p. 2529

[19] Sklyar, A. V. Optimum heating systems for poultry houses / Sklyar, A. V. // Machinery and equipment for rural area. 2014. -No. 1. - p. 26-29.

[20] Marinchenko, T. E. Improving the efficiency of ventilation in the poultry industry / T. E. Marinchenko, A. V. Sklyar, V. I. Minaev, V. V. Mokhov // Problems of the intensification of animal husbandry taking into account environmental protection, EU standards and the production of alternative energy sources, including biogas: Proceedings of XXIV int. scientific conf. Warsaw Publisher: AgencjaWydawniczoPoligraficzna "GIMPO". - 2018. p. 168-170.
[21] Low-power steam turbines - URL: http://www.eltae.ru/pns/low_power_steam_turbines.html (accessed on $11 / 20 / 201 \overline{8})$.

[22] Saracheva, D. A. Gas piston engine mini-CHPs: selection criteria // Achievements, problems and prospects for the development of the oil and gas industry: Proceedings of Int. scientific-practical. conf., dedicated tothe 60th anniversary of higher oil and gas education in the Republic of Tatarstan. Almetyevsk: Almetyevsk State Oil Institute. - 2016. - p. 224225.

[23] Boilers of the DKVR series - URL: http://dkwr.ru/ (accessed on $11 / 20 / 2018$ )

[24] Gusarov, V. A. GTE-10S micro-gas-turbine unit / V. A. Gusarov, V. V. Kharchenko // Bulletin of the VIESH. - 2018. No. 1 (30). - p. 49-55. 